\title{
New insight into the trophic position and ecological role of the European hake (Merluccius merluccius L., 1758) in Central and Southern Tyrrhenian Sea (Central Mediterranean Sea).
}

\author{
Claudio D'Iglio ${ }^{1}$, Nunziatina Porcino ${ }^{2}$, Adriana Profeta ${ }^{2}$, Anna Perdichizzi ${ }^{2}$, Enrico Armeli \\ Milicante $^{2}$, Davide Salvati ${ }^{2}$, Francesco Soraci ${ }^{2}$, Paola Rinelli ${ }^{2}$, and Daniela Giordano ${ }^{2}$ \\ ${ }^{1}$ University of Messina Department of Chemistry Biology Pharmacy and Environmental \\ Sciences \\ ${ }^{2}$ IRBIM CNR
}

April 7, 2021

\begin{abstract}
This paper aims to investigate the ecological role of Merlucicius merluccius, Linnaeus, 1758, in the southern and central Tyrrhenian Sea (GSA 10, Resolution GFCM/33/2009/2 General Fisheries Commission for the Mediterranean), analysing ontogenetic diet shift, geographical variations on prey composition and feeding habits. A sample of 734 hake specimens between $6 \mathrm{~cm}$ and $73 \mathrm{~cm}$ of total length (TL) were collected in 2018. To value the ontogenetic shifts in prey composition, five size-classes were created from the sample and for each class were calculated quantitative feeding indices. The cluster and MDS analysis, based on the \% IRI, resulted in three trophic groups of hake size classes. The most abundant preys for small hake (size class I) were the Euphausiids, Stylocheiron longicorne and Mysidacea, while for hake with size over $10.5 \mathrm{~cm}$ of TL were crustaceans and fish. Engraulis encrasicolus was the most abundant prey fish for hake, followed by Boops boops and Myctophids. The mesopelagic fauna had a relevant role in the European hake diet in the southern zone. The high presence of Euphausiids, Mysids, Myctophidae and Sternoptychidae in the gut content of juvenile hakes $(6-23 \mathrm{~cm})$ showed the importance of organic matter and energy flowed from the mesopelagic environment to the epipelagic. Important is also the presence of decapod crustaceans in hake with size over $36 \mathrm{~cm}$ TL considering that our study area includes an important Gulf for the fishing of decapod crustacea.
\end{abstract}

\section{Hosted file}

Main text.pdf available at https://authorea.com/users/406216/articles/516956-newinsight-into-the-trophic-position-and-ecological-role-of-the-european-hake-merlucciusmerluccius-1-1758-in-central-and-southern-tyrrhenian-sea-central-mediterranean-sea 

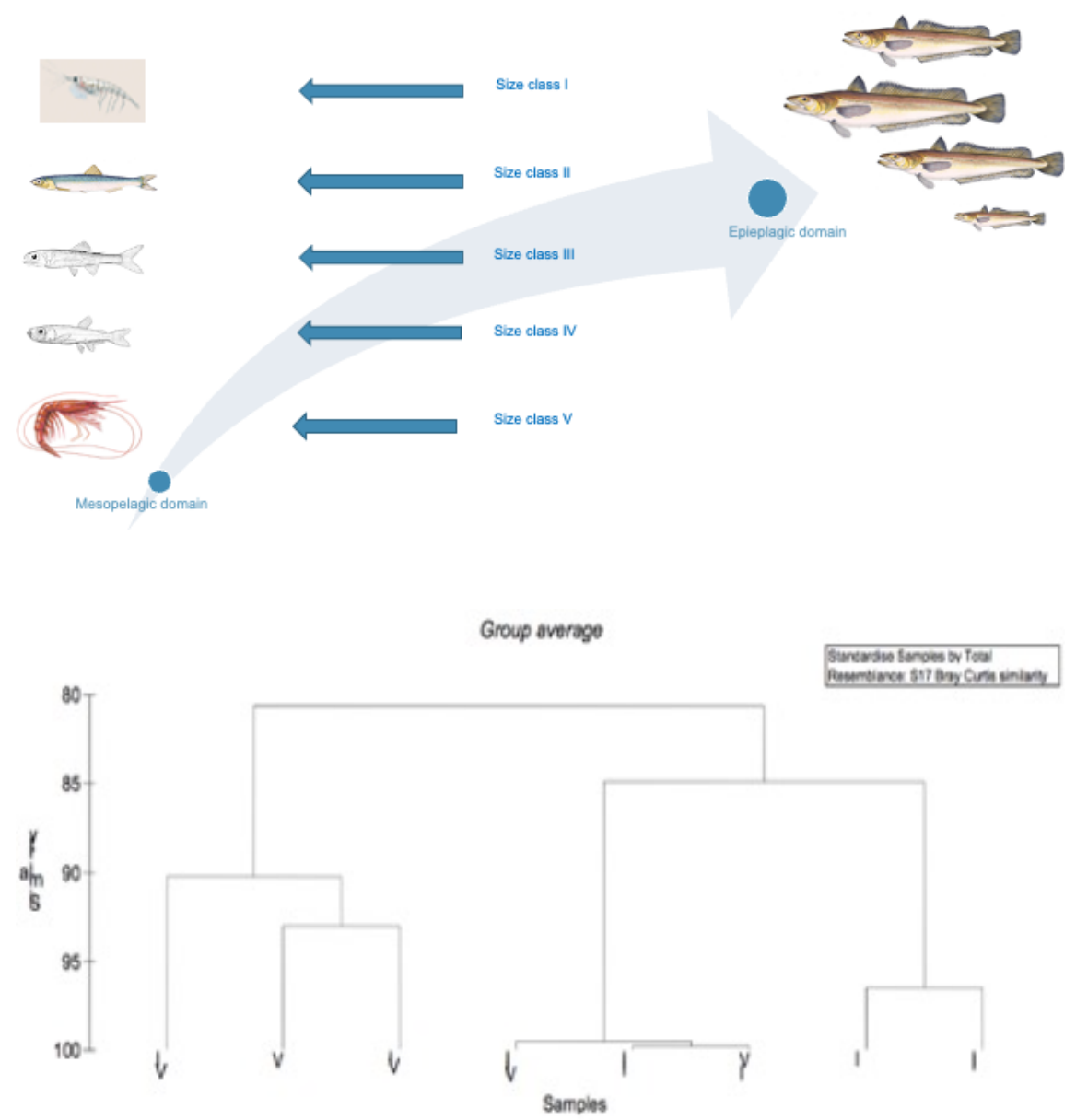


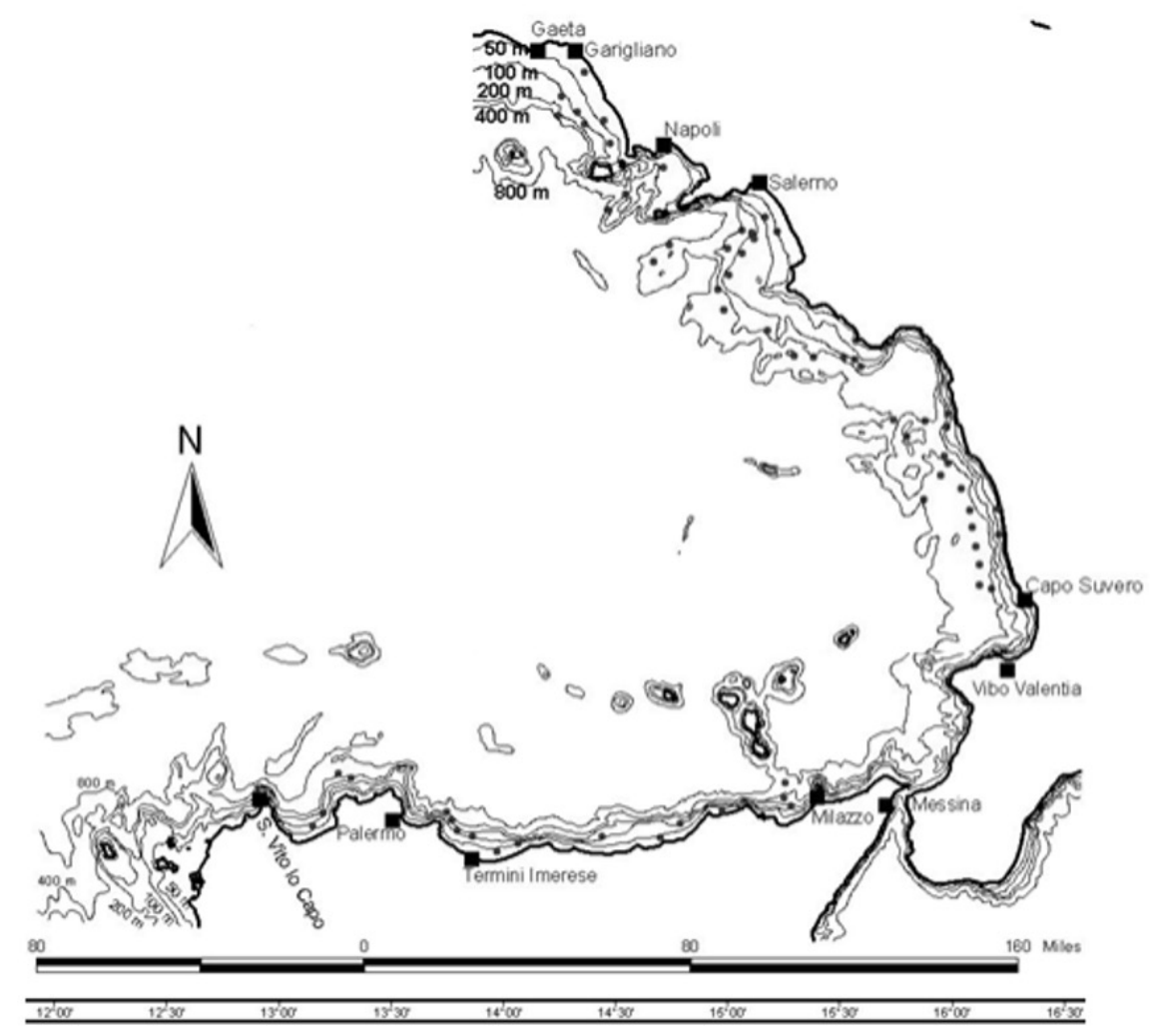

